\title{
REDUCTION OF FINE PARTICLES EXHAUSTED FROM SMALL-SIZE COMBUSTOR USING AGRICULTURAL WASTE RESIDUE BY CONTROLLING BURNING TEMPERATURES
}

\author{
Q. WANG ${ }^{1}$, S. ITOH ${ }^{1} \&$ S. $\mathrm{LU}^{2}$ \\ ${ }^{1}$ Graduate School of Science and Engineering, Saitama University, Japan. \\ ${ }^{2}$ School of Environmental and Engineering, Shanghai University, China.
}

\begin{abstract}
About 3.9 million tons of agricultural residue waste biomass such as rice husk and straw are stably produced from rice each year in Japan. It is reported that vapor pollutants and particles emitted from the burning of agricultural residue waste biomass such as waste rice husk and straw have serious influences on visibility, human health, and global climate. Therefore, it is necessary to utilize waste rice husk and straw effectively to reduce air pollution. In recent years, there has been an increasing demand for the effective utilization of waste agricultural residue biomass instead of fossil fuel in combustors for farming such as greenhouses heating during the winter season. However, there is a lack of regulations or laws to control air pollution from these small-size combustors in Japan. So far, small-size combustors have been characterized by their structural simplicity and low cost. Therefore, it is necessary to evaluate and control the emission of air pollutants such as fine particles (i.e. $\mathrm{PM}_{2.5}$ - particles below $2.5 \mu \mathrm{m}$ in aerodynamic diameter) due to the poor combustion performance of small-size combustors.

In this study, it was investigated whether it would be possible to utilize biomass fuel selected from waste rice husk and straw of agricultural residue waste biomass based on the laboratory combustion experiments. The emission behavior of harmful suspended particulate matter produced from burning rice husk and straw was evaluated by measuring carbonaceous and ionic composition of $\mathrm{PM}_{2.5}$ in the exhaust gases. From the analytical results, it was found that particulate mass concentrations reduced substantially at high-temperature combustion. However, ionic compositions were increased with the increase in combustion temperature. It can be suggested that stable combustion should be performed under suitable conditions to control air pollutants emitted from biomass fuel, although small-size combustors are still not regulated to control $\mathrm{PM}_{2.5}$ emission.
\end{abstract}

Keywords: Agricultural residue waste biomass, carbonaceous composition, combustion conditions, ionic composition, $P M_{2.5}$, rice husk and straw, small size combustors.

\section{INTRODUCTION}

Global warming is increasingly evident in the global climate change. Although one of the main causes for global warming is generally admitted as the consumption of fossil fuel, the use of fossil fuel is expected to still increase because of the economic development and growth of population in the developing countries in near future [1]. Hence, the only solution is zero-emission technology, that is, to reduce all possible emissions produced by human activities to zero [2]. In order to achieve zero emission, it is important to apply new technology for utilizing all biomass [3, 4].

Currently in Japan, most of the waste residue biomass are produced from agriculture and forestry, which are considered as unused material and mostly being incinerated for disposal due to high cost for collection, transport, storage, and the recovery as energy. Moreover, it is required to take the urgent countermeasures for reducing air pollution from burning and illegal incineration of waste biomass. It has estimated that only in Japan around 3.9 million tons of waste rice husk and straw are produced every year, which are the most common agricultural waste residue biomass in the country. Additionally, since rice is the staple food and a regular part of the diet for almost half of the world population, it is important to prevent global warming by the effective utilization of waste rice husk and straw as biomass fuel. In recent years, there is an increasing demand on the utilization of unused biomass instead of usual fossil oil fuel in combustor for farming-greenhouses heating during the 
winter season. The increase in demand for biomass fuel will also increase the cost. Therefore, biomass fuel combustors are generally made in small size and small scale [5]. The small-size combustors are characterized by their structural simplicity and low cost. Although it was found that visible black smoke and pollutants were emitted due to the poor performance of the combustor, still there is a lack of laws and regulations [6, 7]. Therefore, it is also necessary to improve the existing regulations (e.g. the air pollution control act and the waste disposal and public cleaning law) and plot out new countermeasure for the effective utilization of agricultural wastes like rice husk and straw as biomass fuel.

In this study, the model combustion and emission behaviors of waste rice husk and straw biomass as fuel were investigated based on the laboratory experiments. First, the chemical composition of waste rice husk and straw was analyzed to investigate their combustion characteristics. Then, fine particles such as $\mathrm{PM}_{2.5}$ (suspended particulate matter below $2.5 \mu \mathrm{m}$ in aerodynamic diameter) and other air pollutants emitted from the combustion of waste rice husk and straw were measured by sampling $\mathrm{PM}_{2.5}$ and gases in the exhaust under the different combustion conditions. In the case of using a small combustion device, it is necessary to investigate the optimum temperature for the reduction of fine particles exhausted from small-size combustor using agricultural residue waste biomass by controlling burning temperatures. However, there are few reports evaluated the exhaust gas after the burning of biomass at different temperatures. So, the investigation was carried out to determine the possible use of common agricultural waste biomass like rice husk and straw as fuel in laboratory combustion experiment. Thereby, the behavior of $\mathrm{PM}_{2.5}$ emitted from biomass combustion under different temperature conditions was also investigated.

\section{EXPERIMENTAL METHODS}

2.1 Composition analysis of the rice husk and straw as agricultural residue waste biomass

In this study, the samples of agricultural waste residue biomass such as rice husk and straw were collected from the most popular agricultural area, Nigata Prefecture, Japan, and then the proximate and ultimate analyses of rice husk and straw samples were carried out according to the Japanese Industrial Standard (JIS) method of JIS-M8812 and JIS-M8813.

\subsection{Evaluation methods of the combustion characteristics of waste rice husk and straw}

Combustion characteristics of agricultural waste residue biomass of rice husk and straw were analyzed by thermogravimetric differential thermal analysis (TG-DTA, Model DTG-60; Shimadzu Co. Ltd., Japan). All samples were pulverized and then prepared below $250 \mathrm{~mm}$ by several sieves. About $4.0 \mathrm{mg}$ of pulverized samples were heated at a rate of $15^{\circ} \mathrm{C} \mathrm{min}{ }^{-1}$ starting from room temperature to $900^{\circ} \mathrm{C}$. A gas flow rate of $250 \mathrm{~mL} \mathrm{~min}^{-1}$ was used; clean air gas was used as the carrier gas for combustion [8].

2.3 Evaluation of fine particulates of $\mathrm{PM}_{2.5}$ emitted from combustion of waste rise husk and straw

\subsubsection{Air sampling method for exhaust gas collection}

Biomass burning is an important source of primary fine particles in the atmosphere, which can cause the regional air pollution and affect human health. Recently, fine particles (e.g. $\mathrm{PM}_{2.5}$ ) either emitted from biomass burning or generated by photochemical reactions are of great concern because of their effect on health and environment in Japan. For example, coarse particles of suspended particulate matter (particle sizes larger than $2 \mu \mathrm{m}$ ) are unable to enter into the respiratory tract through nose, throat, and pharynges. Therefore, in this study, we believed it is important to determine the fine particulates of $\mathrm{PM}_{2.5}$ emitted from combustion of waste rise husk and straw. 


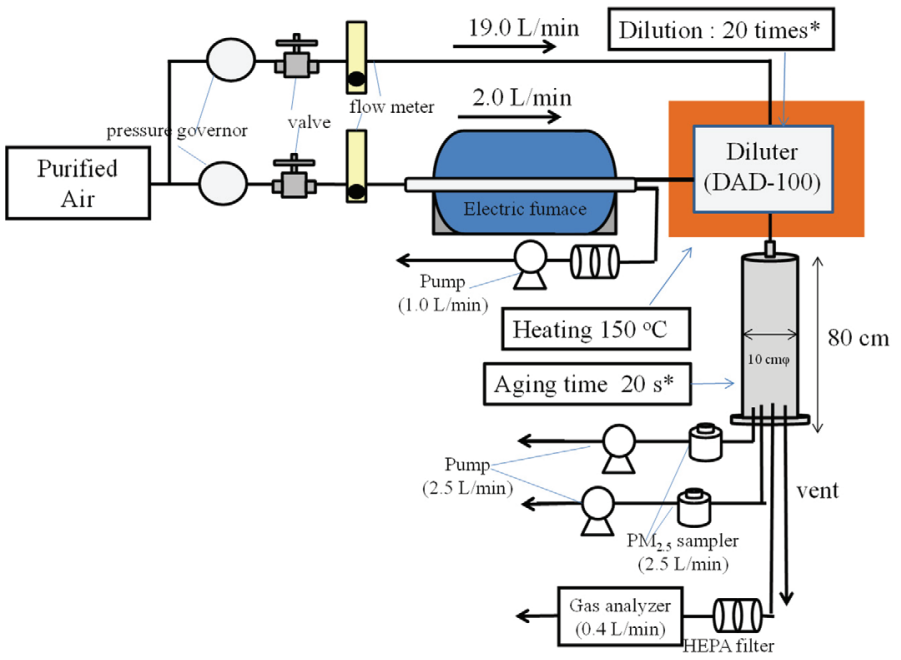

Figure 1: Air sampling setup for exhaust gases emitted from the combustor. *Here, combustion exhaust was diluted 20 times with a special diluter (Dekati DAD-100, Tokyo Dylec Corp., Japan). HEPA: high efficiency particulate air filter.

The collection devices of exhaust gases are shown in Fig. 1. Air flowed into the quartz tube at the rate of $2.0 \mathrm{~L} \mathrm{~min}^{-1}$. Combustion experiments were carried out in fixed-bed combustion system with an annular electric furnace at temperatures $500^{\circ} \mathrm{C}, 600^{\circ} \mathrm{C}, 700^{\circ} \mathrm{C}, 800^{\circ} \mathrm{C}, 900^{\circ} \mathrm{C}$, and $1000^{\circ} \mathrm{C}$. A quartz boat containing sample $(0.2 \mathrm{~g})$ was put into the quartz tube. The rice husk samples were taken after separating the husk from rice. The straw samples were collected from the top, middle, and end portion, where $3 \mathrm{~cm}$ was selected in every portion. A dilution sampler has been extensively used to measure fine particulate emissions from combustion system [9]. The combustion exhaust was diluted 20 times with a diluter (Dekati DAD-100; Tokyo Dylec Corp., Japan). In order to simulate the atmospheric conditions, gas, and particles were collected using an air cooling method. However, to minimize the condensation losses during air sampling, all surfaces of the devices are placed in contact with the exhaust up to the point where the exhaust was mixed with the diluted air present inside. The dilution sampler was electrically heated to maintain the exhaust temperature $150^{\circ} \mathrm{C}$. On entering the chamber, the exhaust was further diluted and rapidly cooled for essentially ambient conditions and aging time was $20 \mathrm{~s}$. In order to evaluate the $\mathrm{PM}_{25}$ emissions from the combustor, exhaust $\mathrm{PM}_{25}$ was collected on the quartz fiber filters (35 mm $\varnothing$, 2500QAT-UP; Pallflex Products Corp.) using two air samplers namely $\mathrm{PM}_{2.5}$ personal sampler (Model NWPS-35HS, Sibata Scientific Technology Co. Ltd., Japan). The quartz fiber filters were precombusted at $900^{\circ} \mathrm{C}$ for $3 \mathrm{~h}$. The quartz fiber filters were used for carbonaceous and ionic composition analysis. Gaseous components $\left(\mathrm{CO}, \mathrm{CO}_{2}, \mathrm{O}_{2}, \mathrm{NOx}\right.$, and $\mathrm{SO}_{2}$ ) were also evaluated by the portable gas analyzer (Model PG-250; Horiba Co. Ltd., Japan).

\subsubsection{Measurement of carbonaceous compositions of organic substances (OC) and elemental} substances (EC) in $\mathrm{PM}_{2.5}$ emitted from the combustor

Carbonaceous analysis was performed by the IMPROVE method (Interagency Monitoring of Protected Visual Environment) using the thermo-optical carbon analyzer (thermo/optical carbon analyzer: Model 2001; Desert Research Institute Co. Ltd., Japan) (Table 1). In this method, a $0.503 \mathrm{~cm}^{2}$ ( $8 \mathrm{~mm}$ diameter) punch aliquot of a sample quartz filter was heated at $120^{\circ} \mathrm{C}(\mathrm{OC} 1), 250^{\circ} \mathrm{C}(\mathrm{OC} 2)$, $450^{\circ} \mathrm{C}(\mathrm{OC} 3)$, and $550^{\circ} \mathrm{C}(\mathrm{OC} 4)$ in a helium atmosphere and then at $550^{\circ} \mathrm{C}(\mathrm{EC} 1), 700^{\circ} \mathrm{C}(\mathrm{EC} 2)$, and 
Table 1: Protocol of IMPROVE thermal/optical method for carbonaceous analysis.

\begin{tabular}{lcc}
\hline \multicolumn{3}{c}{ Thermal/optical method } \\
\hline Fraction & Temperature $\left({ }^{\circ} \mathrm{C}\right)$ & Atmosphere \\
\hline OC1 & 120 & $100 \% \mathrm{He}$ \\
OC2 & 240 & \\
OC3 & 450 & \\
OC4 & 550 & $2 \% \mathrm{O}_{2}+98 \% \mathrm{He}$ \\
EC1 & 550 & \\
EC2 & 700 & \\
EC3 & 800 & \\
\hline
\end{tabular}

$800^{\circ} \mathrm{C}(\mathrm{EC} 3)$ in an oxidizing atmosphere of $2 \%$ oxygen and $98 \%$ helium. The analysis was repeated two or three times for each sample for better accuracy. $\mathrm{PM}_{2.5}$ samples were collected with the $\mathrm{PM}_{2.5}$ personal sampler at the flow rate of $2.5 \mathrm{~L} \mathrm{~min}^{-1}$ for the combustion out on each sampling.

2.3.3 Ionic composition evaluation of waste rice husk and straw

One half of each quartz fiber filter $(35 \mathrm{~mm} \varnothing)$ was ultrasonically extracted with $5 \mathrm{~mL}$ ultrapure water (18.2 $\mathrm{M} \Omega$ milli-Q ultrapure water) for $20 \mathrm{~min}$ to carry out the ionic composition analysis. The concentrations of cations such as $\mathrm{Ca}^{2+}, \mathrm{K}^{+}, \mathrm{NH}_{4}^{+}$, and $\mathrm{Na}^{+}$and anions such as $\mathrm{SO}_{4}{ }^{2-}, \mathrm{NO}^{3-}$, and $\mathrm{Cl}^{-}$were determined in two different ion chromatographs (Model DX-100; Dionex Co. Ltd., Japan).

\section{RESULTS AND DISCUSSIONS}

\subsection{Composition measurement of rice husk and straw as agricultural residue waste biomass}

The bulk composition of biomass in terms of carbon, hydrogen and oxygen (CHO) did not differ much among different biomass sources. Typical dry weight percentages of $\mathrm{C}, \mathrm{H}$, and $\mathrm{O}$ contents were $30 \%-60 \%, 5 \%-6 \%$, and $30 \%-45 \%$ respectively [10]. The results of composition analysis of waste rice husk and straw are presented in Table 2.

The proximate analysis and ultimate analysis of rice husk indicated that ash content was high in waste rice husk and the carbon content was lower in rice straw than in rice husk. It indicated that heating value of waste rice husk was lower than waste rice straw. However, the utilization of waste rice husk and straw as fuel is much lower than fossil fuel. Therefore, it is necessary to find the suitable combustion conditions for the effective utilization of agricultural waste rice husk and straw as fuel.

\subsection{Combustion characteristics of rice husk and straw}

The similar tendencies and behavior of rice husk and straw characterized by TG/DTA analysis are shown in Fig. 2. The TG/DTA thermogram for rice husk and straw showed two well-defined peaks at $280^{\circ} \mathrm{C}$ and around $400^{\circ} \mathrm{C}$. These results represented that rice husk and straw achieved its pyrolysis around $280^{\circ} \mathrm{C}$, where the more volatile components were burnt, but the carbonized fraction was burnt at a higher temperature around $400^{\circ} \mathrm{C}$. For this reason, the waste rice husk and straw can be only combusted above the temperature conditions of $500^{\circ} \mathrm{C}$. Therefore, in this study, combustion 
Table 2: Rice husk and straw composition analysis.

\begin{tabular}{|c|c|c|c|c|c|c|c|c|}
\hline \multirow[b]{2}{*}{ Sample } & \multicolumn{4}{|c|}{ Proximate analysis (wt\%) } & \multicolumn{4}{|c|}{ Ultimate analysis (wt\%) } \\
\hline & M & $\mathrm{VM}$ & Ash & $\mathrm{FC}$ & $\mathrm{C}$ & $\mathrm{H}$ & $\mathrm{N}$ & $\mathrm{O}$ \\
\hline Rice husk & 5.4 & 62.5 & 17.5 & 14.6 & 45.11 & 5.87 & 0.52 & 30.99 \\
\hline Rice straw & 5.3 & 69.2 & 9.2 & 16.3 & 39.19 & 5.26 & 0.51 & 45.89 \\
\hline
\end{tabular}

M: Moisture, VM: Volatile matter, FC: Fixed carbon.

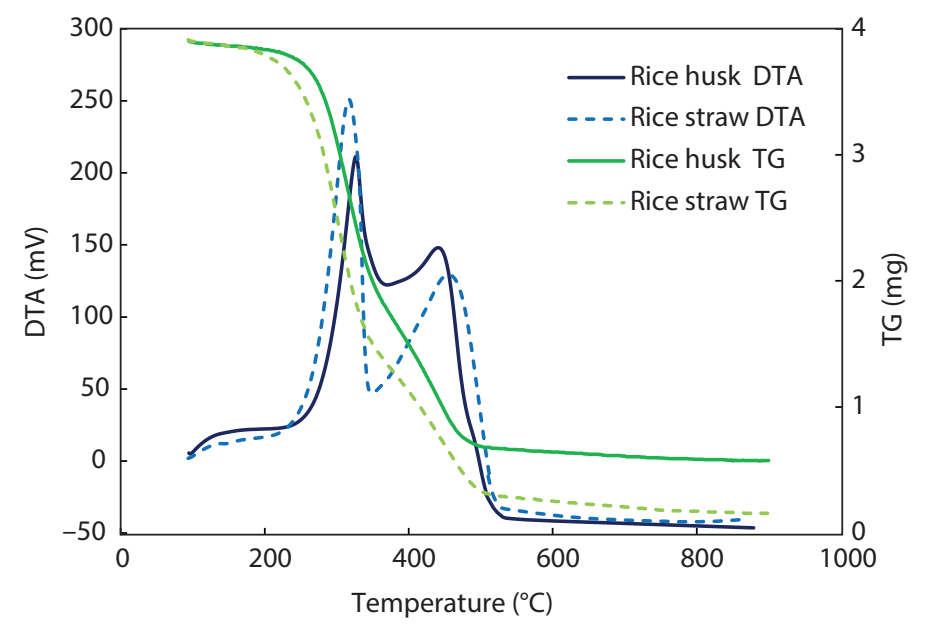

Figure 2: Pyrolysis and combustion behavior of waste rice husk and straw.

experiments were carried out at the interval temperatures of $500^{\circ} \mathrm{C}, 600^{\circ} \mathrm{C}, 700^{\circ} \mathrm{C}, 800^{\circ} \mathrm{C}, 900^{\circ} \mathrm{C}$, and $1000^{\circ} \mathrm{C}$.

3.3 $\mathrm{PM}_{2.5}$ and gaseous components emitted from combustion of waste rice husk and straw under different combustion temperatures

\subsubsection{Gases components and combustion efficiency}

According to the simple combustion efficiency, $>90 \%$ carbon combusted in the fire was emitted in the form of $\mathrm{CO}_{2}$ and $\mathrm{CO}$ and $<10 \%$ carbon was in species such as hydrocarbons and particulate carbon in this study. With this, the modified combustion efficiency (MCE) can be defined as given in eqn (1). Using MCE, the combustion conditions can be categorized as follows: $\mathrm{MCE}<0.9$ indicates smoldering combustion and MCE $>0.9$ indicates flaming combustion [11].

$$
\mathrm{MCE}=\frac{[\mathrm{C}] \mathrm{Co}_{2}}{[\mathrm{C}] \mathrm{co}+[\mathrm{C}] \mathrm{co}_{2}}
$$

The behavior of gaseous components during waste rice husk and straw combustion under different temperatures $\left(500^{\circ} \mathrm{C}-1000^{\circ} \mathrm{C}\right)$ is shown in Fig. 3. It was found that all gas concentrations showed the similar behavior in two temperature ranges like $500^{\circ} \mathrm{C}-700^{\circ} \mathrm{C}$ and $800^{\circ} \mathrm{C}-1000^{\circ} \mathrm{C}$. Figure 4 shows the variation in $\mathrm{MCE}$ under all combustion conditions at the different temperatures. As shown in Fig. 3, at the temperature ranging from $700^{\circ} \mathrm{C}$ to $800^{\circ} \mathrm{C}, \mathrm{CO}$ and $\mathrm{O}_{2}$ concentrations increased 

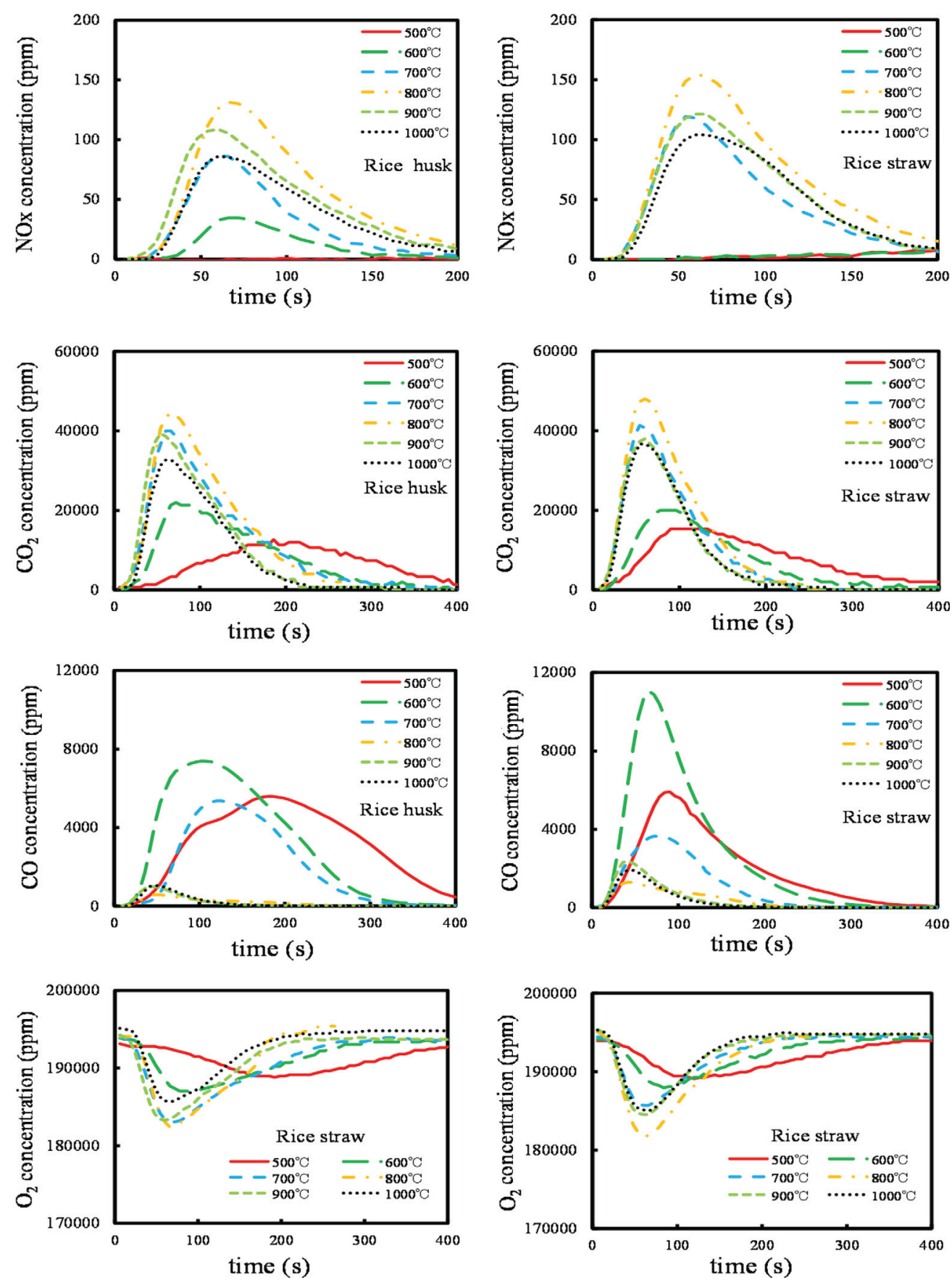

Figure 3: Gas components emitted from combustion of waste rice husk and straw at different combustion temperatures (right: rice husk; left: rice straw). 

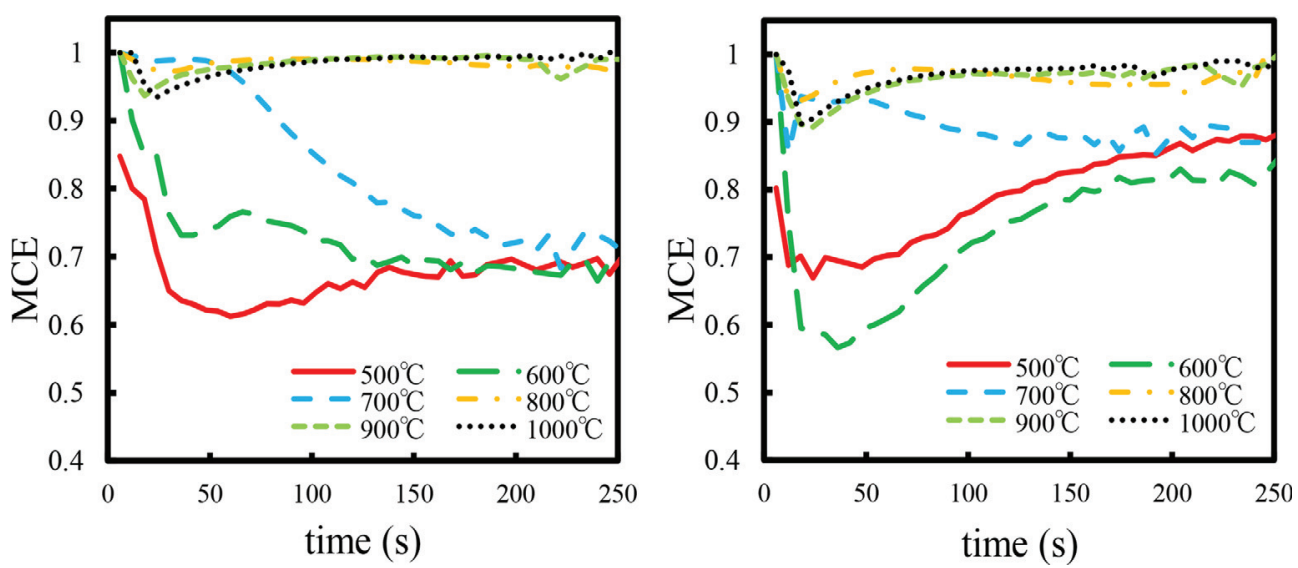

Figure 4: Gas components emitted from combustion of waste rice husk and straw at different combustion temperatures (right: rice husk; left: rice straw).

under smoldering combustion conditions and $\mathrm{NO}_{\mathrm{X}}$ and $\mathrm{CO}_{2}$ concentrations increased under flaming combustion conditions. Since $\mathrm{SO}_{\mathrm{X}}$ concentrations were very lower than its detected limitation, the results are not shown in Fig. 4. These results indicated that the combustion efficiencies under flaming combustion were better than under smoldering combustion condition. Biomass fuel is regarded as a renewable energy source with low $\mathrm{CO}_{2}$ emissions if produced in a sustainable manner. Therefore, if we use waste rice husk and straw as more effective fuel combustion, the contribution of $\mathrm{CO}_{2}$ emission to global warming could be less.

3.3.2 Carbonaceous compositions of organic substances (OC) and elemental substances (EC) in $\mathrm{PM}_{2.5}$ emitted from the combustor

The effect of combustion temperature on carbonaceous compositions in $\mathrm{PM}_{2.5}$ was investigated. The results of carbonaceous composition analysis are shown in Fig. 5. Organic carbon (OC) composition includes biomass markers such as levoglucosan and methoxyphenol [12], which are generated from thermolysis of cellulose and lignin. Levoglucosan is one of the water-soluble organic substances, and it can contribute to cloud condensation nuclei and influence the optical properties of aerosol. In the experimental results, the carbonaceous composition was the lowest when combustion temperature was $700^{\circ} \mathrm{C}$. The concentrations of $\mathrm{OC} 1$ were found to be the highest under smoldering combustion (MCE < 0.9) condition, which was mainly generated by biomass combustion at low temperatures $\left(500^{\circ} \mathrm{C}\right)$. On the other hand, elemental substances (EC) were dominated by $\mathrm{EC} 1$ (char-EC) under smoldering combustion. Under flaming combustion condition (MCE > 0.9), the concentrations of $\mathrm{OC}$ decreased significantly and EC concentrations were dominated by EC2 (soot-EC). However, EC (EC1 + EC2) were emitted under smoldering combustion. Here, EC is mostly POC. POC is pyrolyzed OC simultaneously produced during the biomass combustion under smoldering combustion. Therefore, EC has not been nearly exhausted under smoldering combustion condition (Fig. 5). While determining the total carbonaceous concentration $(\mathrm{OC}+\mathrm{EC})$, it was observed that the carbonaceous concentrations in $\mathrm{PM}_{2.5}$ under flaming combustion condition were 10 times lower than those under smoldering combustion.

The OC/EC ratio in $\mathrm{PM}_{2.5}$ is shown in Fig. 6. The ratios of OC/EC were ranged from 7.28 to 89.33 and 0.30 to 1.23 between smoldering combustion and flaming combustion conditions, respectively. For rice straw, the OC/EC varied from 5.88 to 29.74 (smoldering combustion) and from 0.70 to 3.38 

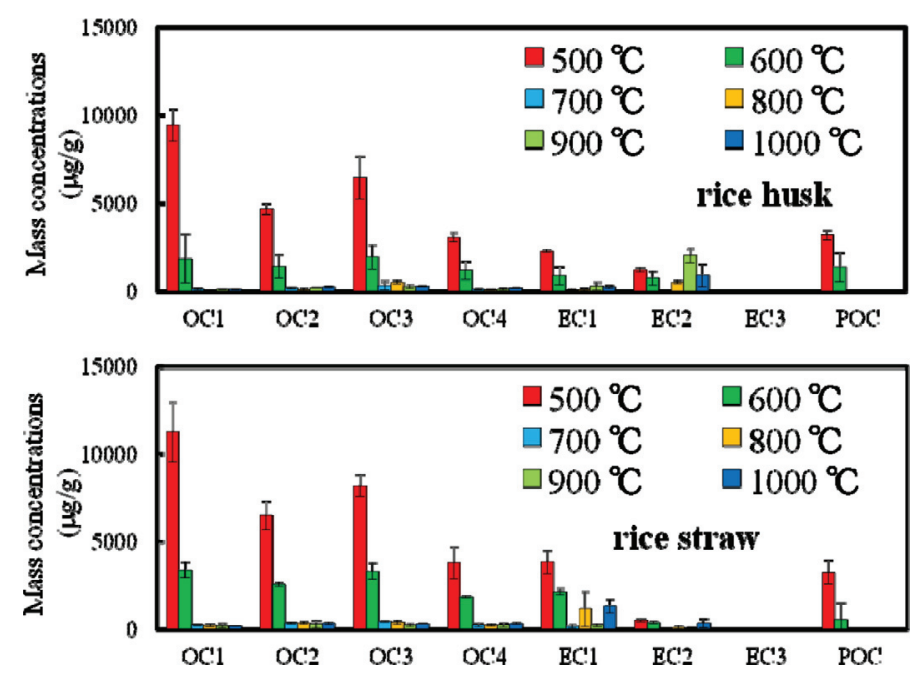

Figure 5: Carbonaceous components in $\mathrm{PM}_{2.5}$ from combustion of rice husk and straw at different combustion temperature (top: rice husk; bottom: rice straw).

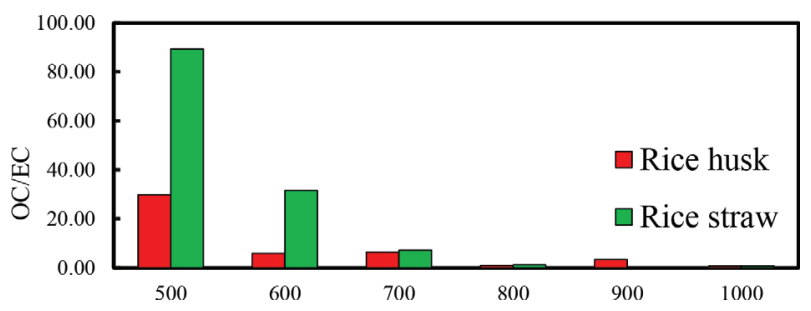

Figure 6: $\mathrm{OC} / \mathrm{EC}$ ratio in $\mathrm{PM}_{2.5}$ from combustion of rice husk and straw at different combustion temperatures.

(flaming combustion). The OC/EC ratio of rice straw is 10 in field burning [13] but 53 in open burning [14]. In this study, we found that the OC/EC ratios ranged from 5.88 to 29.74 under smoldering combustion of rice straw, which are similar trend with the field burning of rice straw [13]. However, the OC/EC ratio under flaming combustion was lower than in the previous study [14].

\subsubsection{Ionic compositions in $\mathrm{PM}_{2.5}$ emitted from the combustor}

Rice husk and straw showed the similar trend in case of ionic concentrations in $\mathrm{PM}_{2.5}$ as presented in Fig. 7. The ionic composition in $\mathrm{PM}_{2.5}$ emitted under flaming combustion condition was twice compared with that under smoldering combustion condition.

The high concentrations of $\mathrm{K}^{+}$and $\mathrm{Cl}^{-}$in $\mathrm{PM}_{2.5}$ were determined at all combustion temperatures. In general, $\mathrm{K}^{+}$is an important component of biomass [15], since it is used in metabolic processes. Therefore, this component can be used as a marker for biomass combustion contributing to air pollution. The experimental results of this study show that the concentrations of $\mathrm{K}^{+}$increases with an increase in combustion temperature. As mentioned above, the behavior of harmful air pollutants emitted from rice husk and straw combustion were investigated by measuring carbonaceous and ionic composition of suspended particulate matter in $\mathrm{PM}_{2.5}$ and the exhaust gases. It will be appreciated if the information of this study can be useful for production and application of small-size combustors [16] by using waste rice 

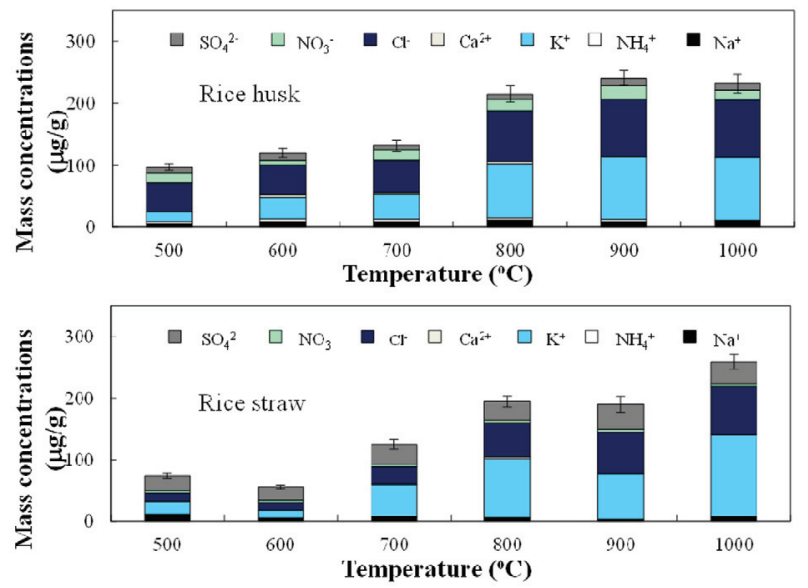

Figure 7: Ionic components in $\mathrm{PM}_{2.5}$ from combustion of rice husk and straw at different combustion temperatures (above: rice husk; bottom: rice straw).

husk and straw or other biomass as fuel. The polycyclic aromatic hydrocarbons emitted from rice husk and straw combustion will be analyzed in further study to reduce the harmful air pollutants effectively.

\section{CONCLUSIONS}

In this study, the possible use of waste rice husk and straw as substitute for fossil fuel was evaluated based on laboratory model combustion experiments. According to the combustion characteristics of rice husk and straw, it is possible to use rice husk and straw as a biomass fuel at the combustion temperatures at least above $500^{\circ} \mathrm{C}$. From the analysis of gaseous compositions, a better efficiency was indicated under flaming combustion condition $\left(800^{\circ} \mathrm{C}-1000^{\circ} \mathrm{C}\right)$ than under smoldering combustion condition $\left(500^{\circ} \mathrm{C}-700^{\circ} \mathrm{C}\right)$. It was found that one tenth of carbonaceous matter in $\mathrm{PM}_{2.5}$ discharged into the flaming combustion compared with smoldering combustion. Similarly, carbonaceous compositions were reduced substantially at flaming combustion state. However, ionic compositions were increased with the increase of combustion temperature.

Air pollutants can be easily reduced if it can be controlled to a stable combustion performance under suitable conditions, especially for developing small-size combustors, and this is the most important information from this study. So, the utilization of agricultural waste biomass instead of fossil fuel will be so much effective by using suitable combustors, and the near future regulations of local air pollution control should be introduced.

\section{ACKNOWLEDGMENT}

Some works of this study were supported by the special funds for Basic Researches (B) (No. 22404022, FY2010-2012) of Grant-in-Aid for Scientific Research of the Japanese Ministry of Education, Culture, Sports, Science and Technology (MEXT), Japan.

\section{REFERENCES}

[1] Saidur, R., Abdelaziza, E.A., Demirbasb, A., Hossaina, M.S. \& Mekhilef, S., A review on biomass as a fuel for boilers. Renewable and Sustainable Energy Reviews, 15, pp. 2262-2289, 2011.doi: http://dx.doi.org/10.1016/j.rser.2011.02.015

[2] Dong, L., Gao, S. \& Xu, G., No reduction over biomass char in the combustion process. Energy Fuels, 24, pp. 446-450, 2010. doi: http://dx.doi.org/10.1021/ef900913p 
[3] Hansen, L.A., Nielsen, H.P., Frandsen, F.J., Dam-Johansen, K., Horlyck, S. \& Karlsson, A., Influence of deposit formation on corrosion at a straw-fired boiler. Fuel Processing Technology, 64, pp. 189-209, 2000. doi: http://dx.doi.org/10.1016/S0378-3820(00)00063-1

[4] Iliopoulou, E.F., Antonakou, E.V., Karakoulia, S.A., Vasalos, I.A., Lappas, A.A. \& Triantafyllidis, K.S., Catalytic conversion of biomass pyrolysis producs by mesoporous materials: effect of steam stability and acidity of Al-MCM-41 catalysts. Chemical Engineering Journal, 134, pp. 51-57, 2007. doi: http://dx.doi.org/10.1016/j.cej.2007.03.066

[5] Johansson, L.S., Tullin, C., Leckner, B. \& Sjovall, P., Particle emissions from biomass combustion in small combustors. Biomass and Bioenergy, 25, pp. 435-446, 2003. doi: http://dx.doi. org/10.1016/S0961-9534(03)00036-9

[6] Simoneit, B.R.T., Biomass burning-a review of organic tracers for smoke from incomplete combustion. Applied Geochemistry, 17, pp. 129-162, 2002. doi: http://dx.doi.org/10.1016/ S0883-2927(01)00061-0

[7] Wiinikka, H. \& Gebart, R., Experimental investigation of the particle emissions from a small-scale pellets combustor. Biomass and Bioenergy, 27, pp. 645-652, 2004. doi: http:// dx.doi.org/10.1016/j.biombioe.2003.08.020

[8] Wang, Q., Itoh, S., Itoh, K., Apaer, P., Chen, Q., Niida, D., Mitsumura, N., Animesh, S., Sekiguchi, K. \& Endo, T., Behavior of suspended particulate matter emitted from combustion of agricultural residue biomass under different temperatures. WIT Transactions on Ecology and the Environment, Vol. 176, Energy and Sustainability IV, eds. C.A. Brebbia, A.M. Marinov \& C.A. Safta, WIT Press: Southampton, pp. 315-325, 2013.

[9] Oliver Chang, M.-C., Chow, J.C., Watson, J.G., Hopke, P.K., Yi, S.-M. \& England, G.C., Measurement of ultrafine particle size distributions from coal-, oil-, and gas-fired stationary combustion sources. Journal of the Air \& Waste Management Association, 54, pp. 1494-1505, 2004. doi: http://dx.doi.org/10.1080/10473289.2004.10471010

[10] Khan, A.A., de Jong, W., Jansens, P.J. \& Spliethoff, H., Biomass combustion in fluidized bed boilers: potential problems and remedies. Fuel Processing Technology, 90, pp. 21-50, 2009. doi: http://dx.doi.org/10.1016/j.fuproc.2008.07.012

[11] Ward, D.E. \& Hao, W.M., Air toxic emissions from burning of biomass globally-preliminary estimates. Proceedings of Air \& Waste Management Assoc. 85th Annual Meeting \& Exhibition, 1992.

[12] Kuo, L.-J., Louchouarn, P. \& Herbert, B.E., Influence of combustion conditions on yields of solvent-extractable anhydrosugars and lignin phenols in chars: implications for characterizations of biomass combustion residues. Chemosphere, 85, pp. 797-805, 2011. doi: http://dx.doi. org/10.1016/j.chemosphere.2011.06.074

[13] Engling, G., Lee, J.J., Tasi, Y.-W., Lung, S.-C.C., Chou, C.C.-K. \& Chan, C.-Y., Sizeresolved Anhydrosugar composition in smoke aerosol from controlled field burning of rice straw. Aerosol Science and Technology, 43, pp. 662-672, 2009. doi: http://dx.doi. org/10.1080/02786820902825113

[14] Hays, M.D., Fine, P.M., Geron, C.D., Kleeman, M.J. \& Gullett, B.K. Open burning of agricultural biomass: physical and chemical properties of particle-phase emissions. Atmospheric Environment, 39, pp. 6747-6764, 2005. doi: http://dx.doi.org/10.1016/j.atmosenv.2005.07.072

[15] Jones, J.M., Darvell, L.I., Bridgeman, T.G., Pourkashanian, M. \& Williams, A., An investigation of the thermal and catalytic behavior of potassium in biomass combustion. Proceedings of the Combustion Institute, 31, pp. 1955-1963, 2007. doi: http://dx.doi.org/10.1016/j.proci.2006.07.093

[16] Wang, Q., Maezono, T., Apaer, P., Chen, Q., Gui, L., Itoh, K., Kurokawa, H., Sekiguchi, K., Sugiyama, K., Niida, H. \& Itoh, S., Characterization of suspended particulate matter emitted from waste rice husk as biomass fuel under different combustion conditions. WIT Transactions on Ecology and the Environment, Vol. 176, Air Pollution XX, WIT Press: Southampton, pp. 365-376, 2012. 